\title{
Caracterização físico-química do mel de abelhas proveniente da florada do cajueiro
}

\author{
Physicochemical characterization of the bee honey originating in the cashew flowering
}

\author{
Juliana do Nascimento Bendini ${ }^{\mathrm{I}}$ Darcet Costa Souza ${ }^{\mathrm{I}^{*}}$
}

\begin{abstract}
O presente trabalho teve como objetivos identificar RESUMO e caracterizar o mel proveniente da florada do cajueiro (Anacardium occidentale L.). O estudo foi realizado a partir de 24 amostras de mel coletadas em apiários distribuidos num cajueiral de aproximadamente 1000 hectares, localizado no município de Cascavel, Estado do Ceará, Brasil. As mesmas foram submetidas a análises melissopalinológicas e físicoquímicas (umidade, acidez total, cinzas, açúcares totais, Lund, $p H$, condutividade elétrica, HMF, atividade de água e densidade). Com base nas análises melissopalinológicas, o mel foi considerado monofloral, proveniente da floradado cajueiro. Os intervalos de variação dos parâmetros físicoquímicos analisados foram: 16,5-19,2\% (umidade), 22-40meq $\mathrm{kg}^{-1}$ (acidez total), 0,182-0,301\% (cinzas), 80,8-83,5\% (açúcares totais), 1,0-2,0mL (Lund), 3,48-3,83 (pH), 179 $198 \mu \mathrm{S} \mathrm{cm}^{-1}$ (condutividade elétrica), 9,6-30,91 $\mathrm{mg} \mathrm{kg}^{-1}$ (HMF), 0,62-0,76 (atividade de água) e 1,33-1,43g $\mathrm{mL}^{-1}$ (densidade). As análises mostraram que o mel da florada do cajueiro apresenta características físico-químicas dentro dos padrões estabelecidos pela legislação vigente.
\end{abstract}

Palavras-chave: mel de abelhas, mel de cajueiro, denominação de origem.

\section{ABSTRACT}

The present study was aimed at the identification and characterization of the bee honey (Apis mellifera) derived from cashew flowers (Anacardium occidentale L.). The study was carried out through the analysis of 24 samples of honey collected from apiaries distributed in a cashew plantation of about 1000 hectares, located in the area around the town of Cascavel, in the state of Ceará, Brazil. The samples were submitted to melissopalinological and physicochemical analysis (humidity, total acidity, ashes, total sugars, Lund, $\mathrm{pH}$, electrical conductivity, $H M F$, water activity, and density). On the basis of the melissopalinological analysis, the honey was considered unifloral, with its origin traced to the cashew flowering. The variation intervals of the physicochemical parameters under analysis were: 16.5-19.2\% (humidity), 22-40meq $\mathrm{kg}^{-1}$ (total acidity), $0.18-0.30 \%$ (ashes), 80.8-83.5\% (total sugars), 1.0 $2.0 \mathrm{~mL}$ (Lund), 3.48-3.83 ( $\mathrm{pH}), 179-198 \mu \mathrm{S} \mathrm{cm}^{-1}$ (electrical conductivity), $9.6-30.91 \mathrm{mg} \mathrm{kg}^{-1}(\mathrm{HMF}), 0.62-0.76$ (water activity), and $1.337-1.437 \mathrm{~g} \mathrm{~mL}^{-1}$ (density). The analyses show that the honey originating from the cashew flowering presents unique physicochemical characteristics which are within the standards established by the current legislation.

Key words: honey, cashew, characterization, origin, identification.

No Nordeste brasileiro, em especial nos Estados do Ceará, Piauí e Rio Grande do Norte, existem grandes áreas de cultivo de cajueiro (Anacardium occidentale L.), utilizadas para a produção de castanha e pedúnculo. Por se tratar de uma cultura atrativa às abelhas melíferas, é possível a produção de mel monofloral a partir dessa florada. Atualmente este mel é produzido e comercializado no mercado nacional e internacional, porém pouco se conhece sobre suas características físico-químicas.

Nesse sentido, a caracterização do mel monofloral proveniente da florada do cajueiro é importante como parte de uma estratégia de valorização desse produto, de identidade regional, podendo agregar valor ao mesmo.

Para assegurar a produção do mel monofloral de caju, utilizou-se um plantio comercial de aproximadamente 1000 hectares, localizado no município de Cascavel, no Estado do Ceará, Brasil, onde já existia

\footnotetext{
IUniversidade Federal do Piauí (UFPI), TROPEN. Av. Universitária, 1000, 64049-550, Teresina, PI, Brasil. E-mail: darcet@terra.com.br.*Autor para correspondência.
} 
a exploração apícola. Foram selecionados para coleta das amostras quatro colméias em três apiários localizados na parte central do plantio, as quais receberam melgueiras vazias. Durante o período de coleta, a floração do cajueiro era exuberante, não havia frutificação e nem outra florada secundária na área. Foram escolhidos, de cada colméia, quatro quadros completamente operculados, dos quais foram retiradas duas amostras, totalizando vinte e quatro amostras.

As amostras de mel foram submetidas à análise melissopalinológica, segundo a metodologia descrita por BARTH (2004). A análise foi realizada no Setor de Apicultura da Universidade Federal do Ceará para verificação da categoria monofloral das amostras.

As análises físico-químicas (umidade, acidez total, hidroximetilfurfural -HMF, açúcares totais, $\mathrm{pH}$, cinzas, condutividade elétrica, Lund, cor, densidade e atividade de água) foram realizadas no Laboratório de Análises de Produtos Apícolas do Centro de Estudos Apícola (CEA) do Departamento de Ciências Agrárias da Universidade de Taubaté-SP. Estas seguiram os métodos estabelecidos pela legislação brasileira, que se encontram descritos na Instrução Normativa no ${ }^{-11}$, de 20 de outubro de 2000, do Ministério da Agricultura Pecuária e Abastecimento (BRASIL, 2000) e as normas internacionais (BOGDANOV et al. 2001; CAC, 1990). Aos resultados obtidos, aplicou-se uma análise de estatística descritiva.

A análise melissopalinológica revelou a dominância do pólen do cajueiro, predominando de $49 \%$ a $81 \%$ em todas as amostras, o que permite considerar o mel analisado como monofloral proveniente da florada do cajueiro. O resultado ratifica observações anteriores que relataram a grande atratividade das flores do cajueiro às abelhas melíferas (FREITAS et al., 2002; VIT, 2003; BHATTACHARYA, 2006). Estas informações fazem das áreas de cajucultura um espaço potencial para a produção de mel, podendo este ser caracterizado como um produto regional.

Os resultados das análises físico-químicas das amostras (Tabela 1) apresentaram, para cada parâmetro, intervalos de variação dentro dos limites estabelecidos na legislação brasileira e internacional (BRASIL, 2000; CAC, 1990).

A média do teor de umidade dos méis foi de $18,46 \pm 0,61 \%$, com os resultados variando entre $16,5 \%$ e $19,2 \%$. A média de umidade do mel do cajueiro equipara-se às médias de méis monoflorais de eucalipto e laranjeira, $18,6 \pm 0,17 \%$ e $18,1 \pm 019 \%$, respectivamente, encontrados por KOMATSU et al. (2002), bem como ao valor médio de $18,06 \%$ encontrado para o mel de algaroba (EVANGELISTA-RODRIGUES et al., 2005).

A média para acidez total nas amostras analisadas foi de $30,21 \pm 4,51 \mathrm{meq}^{-1} \mathrm{e}$ para o $\mathrm{pH}$ foi de
$3,67 \pm 0,09$. SODRÉ \& MARCHINI (2004) eARRUDA et al., (2004) encontraram o valor médio de acidez total de $26,79 \pm 0,23 \mathrm{meq}^{-1}$ e $8,81 \mathrm{meq} \mathrm{kg}^{-1}$, respectivamente, para amostras de méis provenientes de diferentes municípios do Ceará. Dessa maneira, pode-se considerar a acentuada acidez encontrada nas amostras como uma característica própria do mel da florada do cajueiro.

A quantidade média de HMF no mel foi de $14,21 \pm 4,2 \mathrm{mg} \mathrm{kg}^{-1}$. O teor de HMF no mel é um indicador de qualidade (WHITE, 1993) e não está diretamente relacionado à origem floral e/ou geográfica.

Nas amostras, os minerais representam em média $0,2 \%$ do peso total, tendo variado de 0,182 a $0,3 \%$. Segundo WHITE (1993), os teores de minerais nos méis variam de 0,02 a $1,0 \%$ do peso, estando em média na faixa de $0,17 \%$. SILVA et al. (2004) encontraram o valor médio de $0,1 \%$ de minerais nos méis provenientes do Estado do Piauí, enquanto SODRÉ \& MARCHINI (2004) e ARRUDA et al. (2004) obtiveram o valor médio de minerais de $0,197 \%$ e $0,185 \%$, respectivamente, para méis provenientes do Ceará. Assim, pode-se considerar o mel proveniente da florada do cajueiro como tendo acentuados valores de minerais. A quantidade de minerais foi correlacionada positivamente à dominância do pólen do cajueiro nas amostras analisadas, através da regressão linear $(r=0,80)$.

$\mathrm{O}$ mel analisado apresentou condutividade elétrica que variou entre 179 a $198 \mu \mathrm{S} \mathrm{cm}^{-1}$, sendo o valor médio $187 \pm 4,8 \mu \mathrm{S} \mathrm{cm}^{-1}$. A condutividade elétrica é uma característica importante na determinação da origem botânica do mel de abelhas (BOGDANOV et al., 2001).

A média dos resultados da quantidade de aminoácidos do mel do cajueiro foi de 1,75 $\pm 0,29 \mathrm{~mL}$ e pode ser considerada alta quando comparada às médias dos méis monoflorais de eucalipto e laranjeira $(0,6 \pm$ $0,05 \mathrm{~mL}$ e $0,4 \pm 0,02 \mathrm{~mL}$ ), encontradas por KOMATSU et al. (2002). Segundo CRANE (1983), a análise dos aminoácidos constituintes das proteínas do mel é importante por fornecer "impressões digitais", que distinguem um tipo de mel de outros.

O mel do cajueiro apresentou cor âmbar, com resultados que variaram de $85 \mathrm{a} 114 \mathrm{~mm}$ na escala PFUND e sua densidade foi de $1,41 \pm 0,03 \mathrm{gmL}^{-1}$. A média dos resultados referentes à atividade de água foi de $0,72 \pm 0,04$, resultado ligeiramente acima do intervalo relatado por GLEITER et al. (2006), que foi de 0,5 a 0,65.

\section{CONCLUSÕES}

As características físico-químicas observadas no mel proveniente da flor do cajueiro são marcantes e permitem caracterizá-lo como um produto 
Tabela 1- Resultados das analises físico-químicas realizadas nas amostras de mel proveniente da florada do cajueiro.

\begin{tabular}{|c|c|c|c|c|}
\hline Parâmetro & Média & Intervalo & Desvio padrão & Limites BRASIL (2000) \\
\hline Umidade $(\%)$ & 18,46 & $16,5-19,2$ & 0,61 & 20 \\
\hline Acidez total (meq kg-1) & 30,21 & $22-40$ & 4,51 & 50 \\
\hline Cinzas $(\%)$ & 0,2 & $0,18-0,30$ & 0,03 & Máximo 0,6 \\
\hline Açúcares totais $(\%)$ & 81,25 & $80,8-83,5$ & 0,61 & -- \\
\hline Lund $(\mathrm{mL})$ & 1,75 & $1,0-2,0$ & 0,29 & $0,6-3,0$ \\
\hline $\mathrm{pH}$ & 3,67 & $3,48-3,83$ & 0,09 & $3,3-4,6$ \\
\hline Condutividade elétrica $\left(\mu \mathrm{S} \mathrm{cm}^{-1}\right)$ & 187 & $179-198$ & 4,8 & Máximo 800 \\
\hline $\operatorname{HMF}\left(\mathrm{mg} \mathrm{kg}^{-1}\right)$ & 14,21 & $9,6-20,9$ & 4,21 & Máximo 60 \\
\hline Atividade de água & 0,72 & $0,62-0,76$ & 0,04 & $0,5-0,65$ \\
\hline Densidade $\left(\mathrm{kg} \mathrm{L}^{-1}\right)$ & 1,41 & $1,34-1,44$ & 0,03 & $1,3950-1,4239$ \\
\hline
\end{tabular}

próprio das áreas de cajucultura, sendo, portanto, típico da região Nordeste do Brasil.

Sua coloração escura, acidez total acentuada e a quantidade de aminoácidos relativamente alta podem, juntamente com outros parâmetros, como o polínico e sensorial, ser características importantes na denominação da origem geográfica deste mel, agregando assim valor à produção regional.

\section{AGRADECIMENTOS}

À Coordenação de Aperfeiçoamento de Pessoal de Nível Superior (CAPES), ao Grupo Edson Queiroz, ao Grupo de Estudo de Apicultura da UFPI, ao Setor de Apicultura da Universidade Federal do Ceará (UFC) e ao Centro de Estudos Apícolas da Universidade de Taubaté-SP (CEA/UNITAU)

\section{REFERÊNCIAS}

ARRUDA, C.M.F. et al. Características físico-químicas de amostras de méis de Apis mellifera L. 1758 (HYMENOPTERA, APIDAE) da região da Chapada do Araripe, município de Santana do Cariri, Estado do Ceará. Boletim da Indústria Animal, v.61, p.41-150, 2004.

BARTH, O.M. Melissopalynogy in Brasil: a review of pollen analysis of honeys, propolis and pollen loads of bees. Sci Agric, v.61, n.3, p.342-350, 2004.

BHATTACHARYA, A. Flower visitors and fruitset of Anacardium occidentale. Capturado em 02 mai. 2006. On line. Disponível na Internet: http://www.sekj.org/PDF/anv41free/anv41-385.pdf

BOGDANOV, S. et al. Calidad de la miel de abejas y estánderes de control: revisón realizada por la comisión internacional de la miel. 2001. Capturado em $19 \mathrm{dez}$. 2001. On line. Disponível na Internet http:// www.beekeeping.com/articulos/calidad-miel.

BRASIL. Leis, decretos, etc. Instrução Normativa 11, Diário Oficial, 20 de outubro de 2000. Seção 1, p.19696-19697.
CAC. Códex Alimentarius Commission. Official methods of analysis. 2.ed. Roma: FAO, 1990. V.3, supl.

CRANE, E. O livro do mel. 2.ed. São Paulo: Nobel, 1983. 204 p.

EVANGELISTA-RODRIGUES, A. et al. Physical-chemical analysis of honeybee Apis mellifera and Melipona scutellaris on two regions at Paraiba State, Brazil. Ciência Rural, v.35, p.1166-1171. 2005 .

FREITAS, B.M. et al. Identifying pollinators among an array of flower visitors, and the case of inadequate cashew pollination in NE Brazil. In: KEVAN, P. et al. (Eds). Pollinating Bees - The conservation link between agriculture and nature. Brasília: Ministry of Enviroment, 2002. p.229244.

GLEITER, R.A. et al. Influence of type and state of crystallisation on the water activity of honey. Food Chem, v.96, p.441-445, 2006.

KOMATSU, S.S. et al. Análises físico-químicas de amostras de méis de flores silvestres, de eucalipto e de laranjeira, produzidos por Apis mellifera L., 1758 (HYMENOPTERA, APIDAE) no Estado de São Paulo. 2. Conteúdo de açucares e de proteína. Ciênc Tecnol Aliment, v.22, n.2, p.143-146, 2002.

SILVA, C.L. et al. Caracterização físico-química de méis produzidos no Estado do Piauí para diferentes floradas. Rev Bras Eng Agríc Ambient, v.8, n.2-3, p.260-265. 2004.

SODRÉ, G.S.; MARCHINI, L.C. Composição físico-química de méis de Apis melífera de diferentes municípios do Ceará. In: CONGRESSO BRASILEIRO DE APICULTURA, 15., 2004, Natal, RN. Anais... Natal: Confederação Brasileira de Apicultura, 2004. [CD ROM].

VIT, P. Anacardium occidentale L. Ficha botánica de interés apícola en Venezuela, no. 6 Merey. $\operatorname{Rev}$ Fac Farm, v.45, n.1, p.77-79, 2003.

WHITE, J.W. Jr. Honey. In: GRAHAN, J.M. The hive and the honey bee. Illinois: Dadant \& Sons, 1993. Cap.21, p.871-925. 